\title{
Applicability of Preliminary Standards for the Hanok Comfort Evaluation Based on Spatial Indices
}

\author{
Jae-Hyang Kim ${ }^{1}$ and Seung-Hoon Han ${ }^{2, *}$ (]) \\ 1 Department of Architecture and Civil Engineering, Chonnam National University, Gwangju 61186, Korea; \\ 101117@jnu.ac.kr \\ 2 School of Architecture, Chonnam National University, Gwangju 61186, Korea \\ * Correspondence: hshoon@jnu.ac.kr; Tel.: +82-62-530-1646
}

Citation: Kim, J.-H.; Han, S.-H. Applicability of Preliminary Standards for the Hanok Comfort Evaluation Based on Spatial Indices Buildings 2021, 11, 497. https:// doi.org/10.3390/buildings11110497

Academic Editor: Gianpiero Evola

Received: 3 September 2021

Accepted: 20 October 2021

Published: 21 October 202

Publisher's Note: MDPI stays neutral with regard to jurisdictional claims in published maps and institutional affiliations.

Copyright: (c) 2021 by the authors. Licensee MDPI, Basel, Switzerland. This article is an open access article distributed under the terms and conditions of the Creative Commons Attribution (CC BY) license (https:// creativecommons.org/licenses/by/ $4.0 /)$.

\begin{abstract}
There is much discussion of the energy performance of buildings in order to carry out sustainable construction. However, buildings are not simply spaces that offer excellent energy performance, but are based on climate, culture, and context, which for sustainability are factors that also need to be considered. Hanok, a vernacular housing form in Korea, is based on organic characteristics and harmony between nature and human. Hanok aims to avoid the destruction of the surrounding ecosystem and to borrow the natural environment as a passive element. Wood, stone, clay lime and paper are mainly used as building materials. Therefore, hanok has a sustainable value that is different from its energy performance. In this context, it is necessary to analyze whether a hanok is a good space to live in, and a study on comfort performance was conducted. In this study, an analysis of the spatial comfort of Hanok was conducted. This research tried to derive performance indicators to pursue the spatial comfort of hanok that is mainly investigated through correlational analysis. The purpose of this study is, therefore, to find correlations by statistically analyzing user surveys and physical indicators, using Pearson correlation coefficient and regression analysis. This makes it possible to set preliminary standards for hanok comfort and how to consider these in the design stage.
\end{abstract}

Keywords: hanok; spatial; comfort; humidity control; condensation; insulation

\section{Introduction}

\subsection{Background}

There is increasing need to analyze environmental problems within cultural and social contexts, such as human and nature, to improve the quality of life [1]. In addition, for low-carbon green growth, sustainable architecture must be built based on adaptability to life, economic feasibility, the comfort of residents, and social benefits [2]. Abel described a cultural approach to sustainability based on climate, culture, and context, and used the term eco-cultural design [3]. In this respect, vernacular housing seeks a mix of local culture, materials, and resources combined with modern ideas and technologies adapted to conditions that were once available in local architecture [4].

Therefore, even in eco-friendly building certification systems, such as Leadership in Energy and Environmental Design (LEED) [5] and Building Research Establishment Environmental Assessment Method (BREEAM) [6], additional points for vernacular housing are given by using local materials and securing ecological areas.

From this perspective, research is underway on the relevance of vernacular housing to sustainability. In Yahya's study, an ecological approach of vernacular architecture in Jordan was analyzed to evaluate the sustainability of ecological culture [4]. Burcu's study also analyzed sustainable characteristics including culture, land use, durability, building materials and technologies, construction waste, energy efficiency and air quality through the vernacular housing in the region of the eastern Black Sea [7]. This could be the 
focus of new sustainable housing initiatives related to Moor's claims of life adaptability, affordability, occupant comfort and broader social benefits [2].

Hanok, a vernacular housing form in Korea, is based on organic characteristics and harmony between nature and human based on the traditional Korean thought of Confucianism, Buddhism, Taoism, and Fengshui [8]. Hanok aims to avoid the destruction of the surrounding ecosystem, to achieve harmony, and to borrow the natural environment as a passive element [9]. Therefore, wood, stone, clay, lime, and paper are mainly used as building materials, and only small amounts of metals and painting materials are used. Table 1 shows the materials used for each structure.

Table 1. Materials and structure of the hanok.

\begin{tabular}{ccc}
\hline Division & Material & Area of Use \\
\hline Wood & Pine & Eranite \\
Stone & $\begin{array}{c}\text { Roofing Tile (Gi-wa) } \\
\text { Brick-shaped Stone }\end{array}$ & $\begin{array}{c}\text { Cornerstone, Stonework, Stone Platform, Wall, Door } \\
\text { Roof, Wall, Door } \\
\text { Stylobate, Wall }\end{array}$ \\
\hline Soil & Soil & Wall \\
Lime & Roof, Wall \\
\hline Paper & Straw & Roof, Wall \\
\hline Metal & Han-ji & Windows \\
\hline
\end{tabular}

The Green Standard for Energy and Environmental Design (G-SEED) [10], Korea's eco-friendly building certification system, gives points for the use of local materials and the securing of ecological area, like LEED and BREEAM. Therefore, hanok as vernacular housing is one of the means to realize sustainable architecture. However, the number of hanok continues to decrease. The number of hanok in Seoul, the capital of Korea, was estimated to have decreased from about 130,00 in the early 1960s, to 24,000 in the early 2000s [11]. This is because the efficient aspects of use and energy consumption are evaluated as disadvantages. Traditional earthen walls (Hwangto) used in hanok have a high thermal conductivity of (1-2) W/ $\mathrm{m}^{2}$, and the insulation effect of windows made of paper is very low [12]. Therefore, it has been shown that hanok emits the most carbon during the building operation phase of the building's life [13]. To compensate for these problems, modern materials, such as insulation and glass windows, are applied. Through this, analysis shows that the energy load of hanok can be reduced by up to $73 \%$, and the future value is also expected to be promising [14]. Since hanok is an ecological building that reflects cultural and social contexts, such as human and nature, changes in the intrinsic value of the materials should be avoided. From this point of view, it is necessary to discuss the intrinsic value of the serenity and comfort of hanok felt from the materials $[15,16]$.

\subsection{Purpose and Method of the Study}

With the recent emergence of hanok that combines modern technologies, it is necessary to analyze whether the value of serenity and comfort of hanok is being maintained. However, a qualitative judgment is required, since the criteria for judging serenity and comfort are very vague. Therefore, the purpose of this paper is to analyze the evaluation method for some items of comfort that is the intrinsic value of hanok and to investigate the survey to establish its standards.

Through our previous research, analyses of comfort factors were conducted, and quantitative measurement methods were considered. At the same time, a qualitative basis was prepared for judgment by conducting a survey on comfort factors for residents of hanok. Thus, regression analyses were adopted as a method to establish the relationship between quantitative and qualitative factors as a statistical method that derives a linear 
regression equation derived from two or several factors. This method is expected to represent the relationship between cost and aesthetic preference or various adjective expressions too $[17,18]$.

In this paper, a series of items such as comfort, humidity control, insulation, and condensation, are targeted. Those items are based on previous researches and a Korean Standard, A 6300 (KS A 6300) [19,20]. After that, quantitative measurements and surveys were conducted on hanok villages in the eastern (Gangneung), central (Eunpyeong) and southern (Hwasun) parts of Korea. In addition, a follow-up survey was conducted on western-style townhouses adjacent to Hwasun Hanok Village for comparison to hanok. Based on this, regression analyses and explorations of the evaluation criteria could be carried out.

\section{Framework for Research Analysis}

\subsection{Evaluation Criteria for the Hanok Comfort}

Kim derived twenty-nine comfort factors based on previous studies related to comfort, and among them, summarized fourteen performance factors related to physical perception [19]. Physical perception elements were divided into olfactory, visual, auditory, tactile, and other elements. The olfactory element was composed of breathability, deodorization, and cleanliness, while the visual element was divided into natural and artificial lighting performance. The auditory element was divided into sound insulation performance and sound absorption performance. The tactile elements were classified into solar radiation, airtightness, insulation, and humidity control. In addition, harmlessness, methodicalness, and maintainability were classified into other factors.

The items related to standardization of comfort performance and environmental characteristics of traditional hanok were submitted to the Ministry of Trade, Industry and Energy of the Republic of Korea with nine physical perception elements and five psychological perception elements, and Table 2 shows the composition [20]. In the above study, an assessment with an analytic hierarchy process (AHP) method was conducted toward architects and hanok experts, and each weight was set [20]: AHP is normally used for decision-making and plays a role of the analyzer to determine priorities by measuring the relative importance between evaluation items. Currently, fourteen items have been registered as an industry standard (KS A 6300), and a test method has been established for each item [21].

Table 2. Comfort performance item of the traditional hanok.

\begin{tabular}{ccc}
\hline & Evaluation Item & Weight \\
\hline & Humidity Control & 6.71 \\
& Condensation & 3.91 \\
Physical & Air Cleanness & 3.73 \\
Perceptive Factors & Airtightness (Air Permeability) & 5.04 \\
(49.95) & Insulation & 3.91 \\
& Solar Radiation & 5.70 \\
& Thermal Comfort & 5.76 \\
& Sound Insulation & 5.75 \\
& Solar Lighting & 9.44 \\
\hline Psychological & Scenery & 11.58 \\
Cognitive Factors & Beauty & 12.53 \\
(50.05) & Deodorization & 11.18 \\
& Usability & 10.18 \\
& Health & 4.40 \\
\hline
\end{tabular}

Through comparison between KSA6300 [21] and Kim's research [19], some of the physical perception and comfort elements of hanok are evaluated by being integrated with other comfort factors. In addition, condensation properties were added and evaluated. Psychological cognitive factors are evaluated in five categories: canonicality, aesthetics, 
anti-smoke, usability, and health, and the analysis was conducted in previous studies [16]. The nine physical perception elements can be classified into two categories, one that directly affects the senses of the human body, and one that indirectly affects the human senses. Factors that directly affect each of the four senses are factors that can directly affect each. They can be classified into olfactory-purity, sight-light, auditory-sound insulation, tactilebreathability, warmth, and solar radiation. Factors that indirectly affect the human senses are the performance of the space or material composition. Humidity control, condensation, and insulation are applicable. These indirectly influencing factors are also used for evaluations of the material or its composition in the KS A 6300 evaluation method. In the case of humidity control, the penetration coefficient of the material of the wall, the temperature difference ratio (TDR) of the material for condensation, and the heat transmission rate of the material for insulation are evaluated. On the other hand, the factors that directly affect the environment are evaluated for indoor air quality, luminance, air inflow, predicted mean vote (PMV), and solar radiation analysis. This study excluded directly affected comfort performance analysis. The research scope is limited to only the comfort performance of the space that can indirectly affect the user.

\subsection{Analysis of the Evaluation Method of Spatial Comfort}

Regarding the evaluation of the comfort of hanok, KS A 6300 proposed evaluation methods for nine physical perception elements. This study targets humidity, condensation, and insulation, which among the nine physical perception elements, correspond to spatial comfort. Therefore, an analysis of the evaluation method for humidity control, condensation, and insulation was conducted.

\subsubsection{Humidity Control}

The humidity control evaluation method specified in KS A 6300 is in accordance with KS F 2611. It is intended for a test body made identical to the wall used in actual construction of $200 \mathrm{~mm} \times 200 \mathrm{~mm}$. KS F 2611 [22] was prepared based on ISO 24353 [23] Hygrothermal performance of building materials and products-Determination of moisture adsorption/desorption properties in response to humidity variation. Moisture penetration coefficient is obtained through moisture absorption and moisture resistance tests. The humidity control test is evaluated by the moisture permeability coefficient of the wall used in the hanok, but it is difficult to evaluate the actual hanok in the living room, because the same sample as the actual wall must be made or collected. Also, in the case of KS F 2611, the evaluation of materials is more appropriate than the evaluation of complex walls, so this test method is difficult to apply to the established hanok. For this reason, a measurement method using a hygrometer was made to evaluate the humidity level in the building in which a person resides. Humidity evaluation through measurement using a hygrometer has been mainly applied to museum storage [24]. However, in the case of museum storage, it is evaluated through the relative humidity, so it has limitations in monitoring the moisture absorption and moisture-proof performance of the material itself. In particular, in the case of indoors, the relative humidity is more affected by the room temperature than by the amount of moisture contained in the air, so it is not appropriate to measure the moisture absorption and moisture-proof performance of materials required in the KS test. Therefore, in this paper, the humidity control performance of hanok was evaluated by decreasing and increasing the absolute humidity indoors and outdoors.

\subsubsection{Thermal Insulation}

Insulation is to be evaluated by measuring the heat transmission rate. KS A 6300 satisfies the heat permeation rate [25] for each area of buildings notified by the Ministry of Land, Infrastructure and Transport of the Republic of Korea. However, in the case of hanok, it is very difficult to apply this standard, so an exception is made through the Act on the Promotion of Architectural Assets such as Hanok [26]. Through model tests, it was also found that materials with a large volume of wood, such as the pillars and girders (dori 
in Korean) of hanok, have a greater insulation effect than the calculated value of the heat transmission rate [27]. In addition, since the heat transmission rate of the building part by region is an indicator of the energy performance of the building as the energy saving design standard of the building, there is also a difference between the comfort analysis and the direction to evaluate the inherent value of hanok.

\subsubsection{Condensation}

Condensation evaluation is performed by confirming condensation through a chamber according to KS F 2295 [28], or by calculating the TDR through computer simulation [29]. TDR is calculated by dividing the difference between the indoor temperature and the minimum temperature of the indoor surface as the difference between the indoor temperature and the outdoor temperature, as shown in Equation (1):

$$
T D R=\frac{T_{i}-T_{m}}{T_{i}-T_{o}}
$$

$T_{i}$ means 'Indoor Temperature,' $T_{o}$ is 'Outdoor Temperature,' and $T_{m}$ indicates 'Minimum Indoor Surface Temperature' at the above formula. Condensation evaluation through TDR can be simulated through detailed drawings and actual measurements of the established hanok. Currently, in Korea, design standards for preventing condensation in apartment houses $((0.25-0.28)$ for wall joints) exist [30]. However, this is a criterion that is evaluated only for apartment houses. In the case of hanok, the principle of ventilation and humidity control, which can affect condensation, is different from that of apartment houses, so it is necessary to review the standards that reflect the specificity of hanok.

\section{Spatial Comfort Analysis and Survey Evaluation}

\subsection{Overview of Spatial Comfort Measurement}

Space comfort is evaluated by humidity control, insulation, and condensation. KS A 6300 suggests several methods to measure comfort, but some items are difficult to apply for the hanok that is actually built and inhabited, and the evaluation criteria are also ambiguous. Therefore, in this study, a review was conducted of the newly devised spatial comfort measurement method and standard by selecting four hanok that are actually inhabited and one western-style house that can be compared.

Gangneung Hanok Village, Eunpyeong Village Hall, Literature Hall at Eunpyeong Village, and Hwasun Haesal Hanok Village were selected as local hanoks that can represent the climate of each region in Korea as shown on Figure 1. These regions are located in the south and north, respectively, representing the climate of the coldest and warmest regions in Korea. A set of average, minimum and maximum temperatures, an average relative humidity, and total solar radiation of Gangneung, Eunpyeong and Hwasun in 2020 are shown in Table 3 [31]. In addition, one western-style house located in Hwasun Haesal Village was selected to conduct a comparative analysis of hanoks and western-style houses.

Table 3. Climate information for each region.

\begin{tabular}{cccccc}
\hline Division & $\begin{array}{c}\text { Average } \\
\text { Temperature }\end{array}$ & $\begin{array}{c}\text { Minimum } \\
\text { Temperature }\end{array}$ & $\begin{array}{c}\text { Maximum } \\
\text { Temperature }\end{array}$ & $\begin{array}{c}\text { Average } \\
\text { Relative Humidity }\end{array}$ & $\begin{array}{c}\text { Total } \\
\text { Solar Radiation }\end{array}$ \\
\hline Gangneung & $14.3^{\circ} \mathrm{C}$ & $-10.3^{\circ} \mathrm{C}$ & $36.5^{\circ} \mathrm{C}$ & $60.9 \%$ & $5151.77 \mathrm{MJ} / \mathrm{m}^{2}$ \\
Eunpyeong & $13.2^{\circ} \mathrm{C}$ & $-12.9^{\circ} \mathrm{C}$ & $35.4{ }^{\circ} \mathrm{C}$ & $63.4 \%$ & $5116.25 \mathrm{MJ} / \mathrm{m}^{2}$ \\
Hwasun & $14.5^{\circ} \mathrm{C}$ & $-8.9^{\circ} \mathrm{C}$ & $34.4{ }^{\circ} \mathrm{C}$ & $70.9 \%$ & $5514.17 \mathrm{MJ} / \mathrm{m}^{2}$ \\
\hline
\end{tabular}




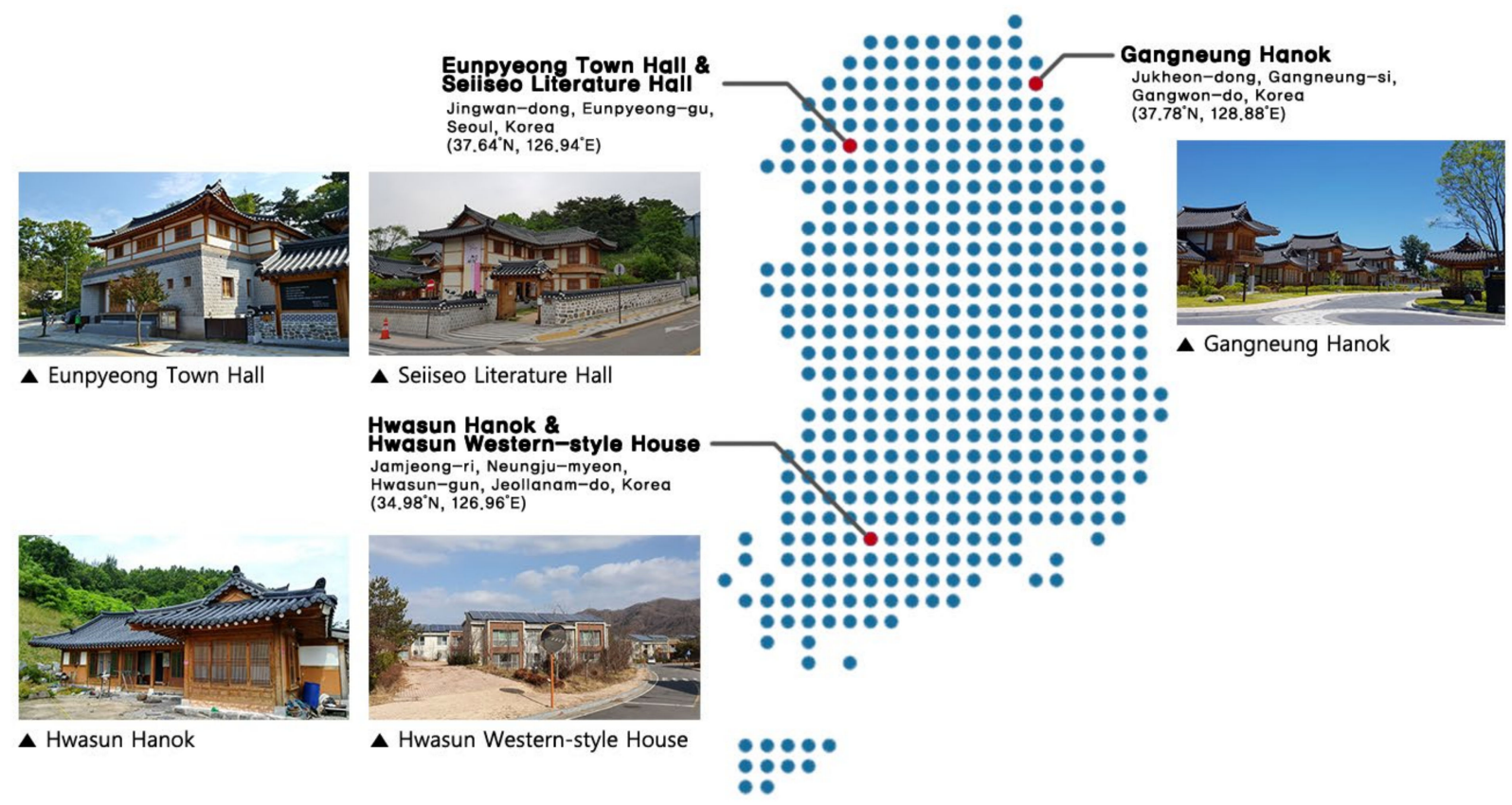

Figure 1. Evaluation place and location.

The scale and composition of the selected hanok and western-style houses is as follows. Gangneung Hanok is a two-story building designed for accommodation. It consists of four rooms and two living rooms called maru. The total floor area is $104.4 \mathrm{~m}^{2}$. Eunpyeong Village Hall was planned as a neighborhood living facility. It has one basement floor and two above ground floors, and consists of two meeting rooms, four rooms, and two living rooms. It has a total floor area of $249.16 \mathrm{~m}^{2}$. The original purpose of Literature Hall at Eunpyeong Village was a residential facility, but it is currently being used as a museum. It consists of five rooms and one living room. It is a two-story building with a total floor area of $142.2 \mathrm{~m}^{2}$. Hwasun Hanok was planned as a residential facility with one floor. It has three rooms and one living room as maru, with a total floor area of $99.59 \mathrm{~m}^{2}$. The Hwasun western-style house unit consists of four bedrooms and one living room, with a total floor area of $130.91 \mathrm{~m}^{2}$. The building was intended for residential use.

Since Korea has four distinct seasons, measurements were made for the seasons that can reflect the climate of each season. These include summer solstice, major heat, frost descent, winter solstice, and major cold. Table 4 shows the evaluation of each season for the four hanok and one western-style house.

Table 4. Presence or absence of evaluation according to the season.

\begin{tabular}{cccccc}
\hline Division & $\begin{array}{c}\text { Summer } \\
\text { Solstice }\end{array}$ & $\begin{array}{c}\text { Major } \\
\text { Heat }\end{array}$ & $\begin{array}{c}\text { Frost } \\
\text { Descent }\end{array}$ & $\begin{array}{c}\text { Winter } \\
\text { Solstice }\end{array}$ & $\begin{array}{c}\text { Major } \\
\text { Cold }\end{array}$ \\
\hline $\begin{array}{c}\text { Gangneung Hanok } \\
\text { Eunpyeong Village Hall }\end{array}$ & $\mathrm{O}$ & $\mathrm{O}$ & $\mathrm{O}$ & $\mathrm{O}$ & $\mathrm{X}$ \\
Literature Hall at Eunpyeong Village & $\mathrm{O}$ & $\mathrm{X}$ & $\mathrm{O}$ & $\mathrm{X}$ & $\mathrm{X}$ \\
Hwasun Hanok & $\mathrm{O}$ & $\mathrm{X}$ & $\mathrm{O}$ & $\mathrm{O}$ & $\mathrm{O}$ \\
Hwasun Western-style House & $\mathrm{O}$ & $\mathrm{O}$ & $\mathrm{O}$ & $\mathrm{O}$ & $\mathrm{O}$ \\
\hline
\end{tabular}

Measurements were carried out in a representative hanok for five major seasons. The survey evaluation was conducted at the same time. The composition of the questionnaire was composed of three questions: comfort, need for facilities, and relative comparison of western-style houses based on previous studies [16]. Accurate comparison of physical measurements and surveys requires data on the entire process of hanok living in the village 
and data for the period. However, this study has a limitation in that it is analyzed only for the representative viewpoint and space.

\subsection{Humidity Analysis}

\subsubsection{Measurement of Physical Indicators (Humidity)}

Humidity measurement measures the absolute humidity indoors and outdoors at the same time, and through this, the magnitude of the moisture absorption and moisture-proof action was analyzed. It was measured every $24 \mathrm{~h}$. Since the absolute humidity can be temporarily increased by special indoor activities (for example, cooking, showering), it was measured as an average of $50 \%$, excluding the difference in absolute humidity between the top $25 \%$ and the bottom $25 \%$. Measurements were made for the five seasons of summer solstice, major heat, frost descent, Winter solstice, and major cold. Figure 2 shows the measured data, and the upper value is the average value of $50 \%$ excluding the upper $25 \%$ and lower $25 \%$ values.

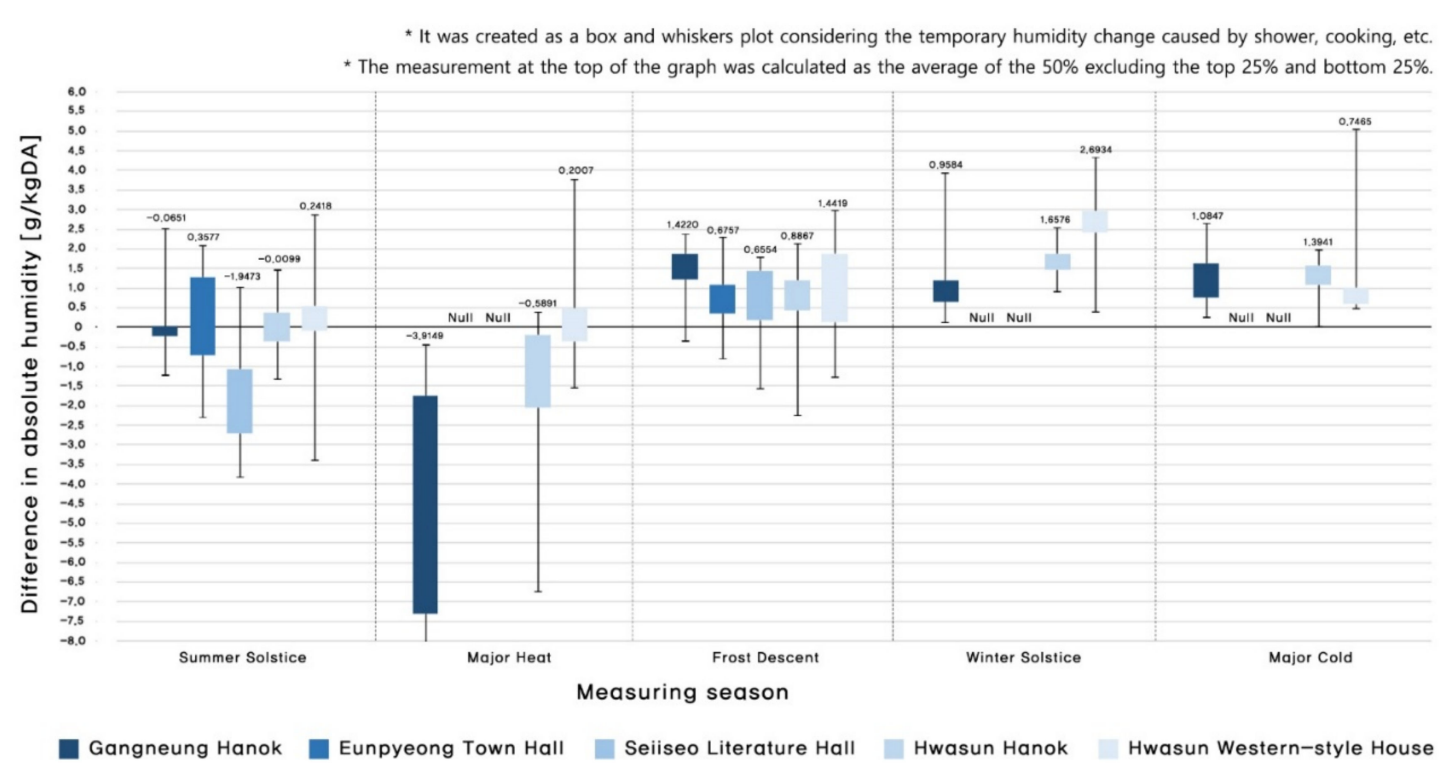

Figure 2. Difference in absolute humidity indoors and outdoors by season.

When comparing the whole control group, the change in absolute humidity of each hanok was different, but it was confirmed that the decrease and increase of the absolute humidity according to the seasons showed a certain tendency. In the case of frost descent, winter solstice, and major cold, it was confirmed that the absolute humidity of the hanok indoors was measured higher than that of the outdoors. It can be explained that the moisture-proof effect of hanok took place. In the case of the summer solstice and major heat, it was confirmed that the indoor absolute humidity of hanok tends to be measured lower than that of outdoors. This can be explained by the dehumidification of hanok.

The moisture-proof action against frost descent, winter solstice, and major cold was recorded as a value that showed no significant difference in either Korean or western-style houses. However, the absolute humidity for summer solstice and major heat shows a big difference. In the case of western-style houses, the difference in absolute humidity was (0.2418 to 0.2007$) \mathrm{g} / \mathrm{kgDA}$, and both positive values were recorded. On the other hand, Gangneung Hanok measured ( -0.0651 to -3.9149$) \mathrm{g} / \mathrm{kgDA}$, Eunpyeong Village Hall had (0.3577 to Null) g/kgDA, Literature Hall at Eunpyeong Village had ( -1.9473 to nil) g/kgDA, and Hwasun Hanok had ( -0.0099 to -0.5891$) \mathrm{g} / \mathrm{kgDA}$. Most Hanoks were measured negatively except for Eunpyeong Village Hall in the condition of dehumidification normally. Western-style houses are expected to appear as features, because they have a very enclosed structure for the energy performance of the building. In the case of 
Eunpyeong Village Hall, it is expected that the dehumidification function was not active, as it was constructed underground.

\subsubsection{Survey Score (Humidity)}

User evaluation was collected by prior research, and analysis was conducted using this [16]. The questionnaire was composed of three questions, each of which corresponded to the relative comparison of the comfort of the senses, the need for facilities, and westernstyle houses within the space. To explore the relationship between the physically measured indicator and the average of the scores of the users for three questions, a comparison was conducted by graph, as shown in Table 5 . A total of five-hundred twenty-four surveys were collected. For the users of the target building, one-hundred thirty-one surveys during the summer solstice period, eighty-five surveys during the major heat period, one-hundred twenty-two surveys during the frost descent period, ninety-two surveys during the winter solstice period, and ninety-four surveys during the major cold period were conducted.

Table 5. Comparison between the absolute humidity difference and survey score.

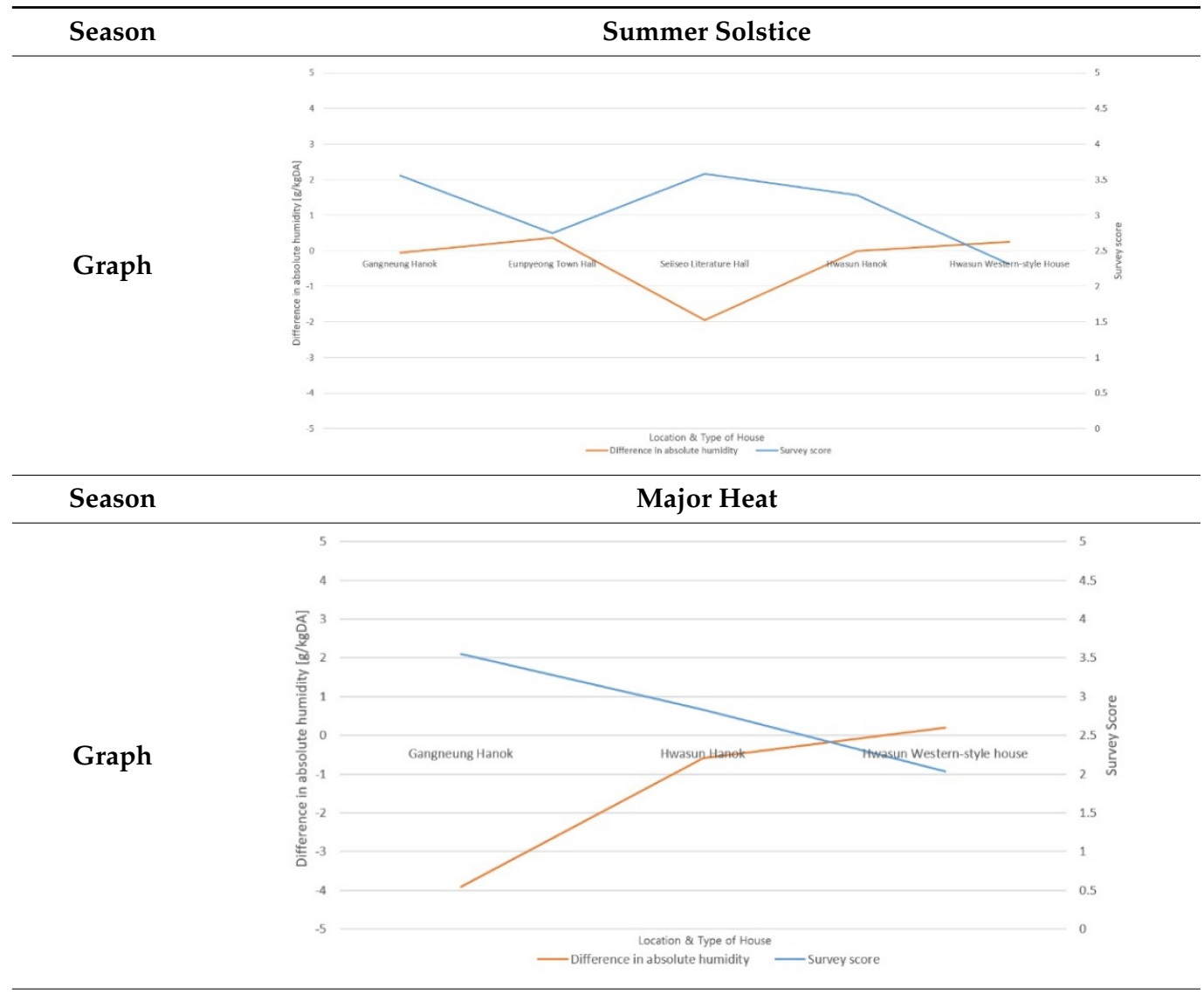


Table 5. Cont.

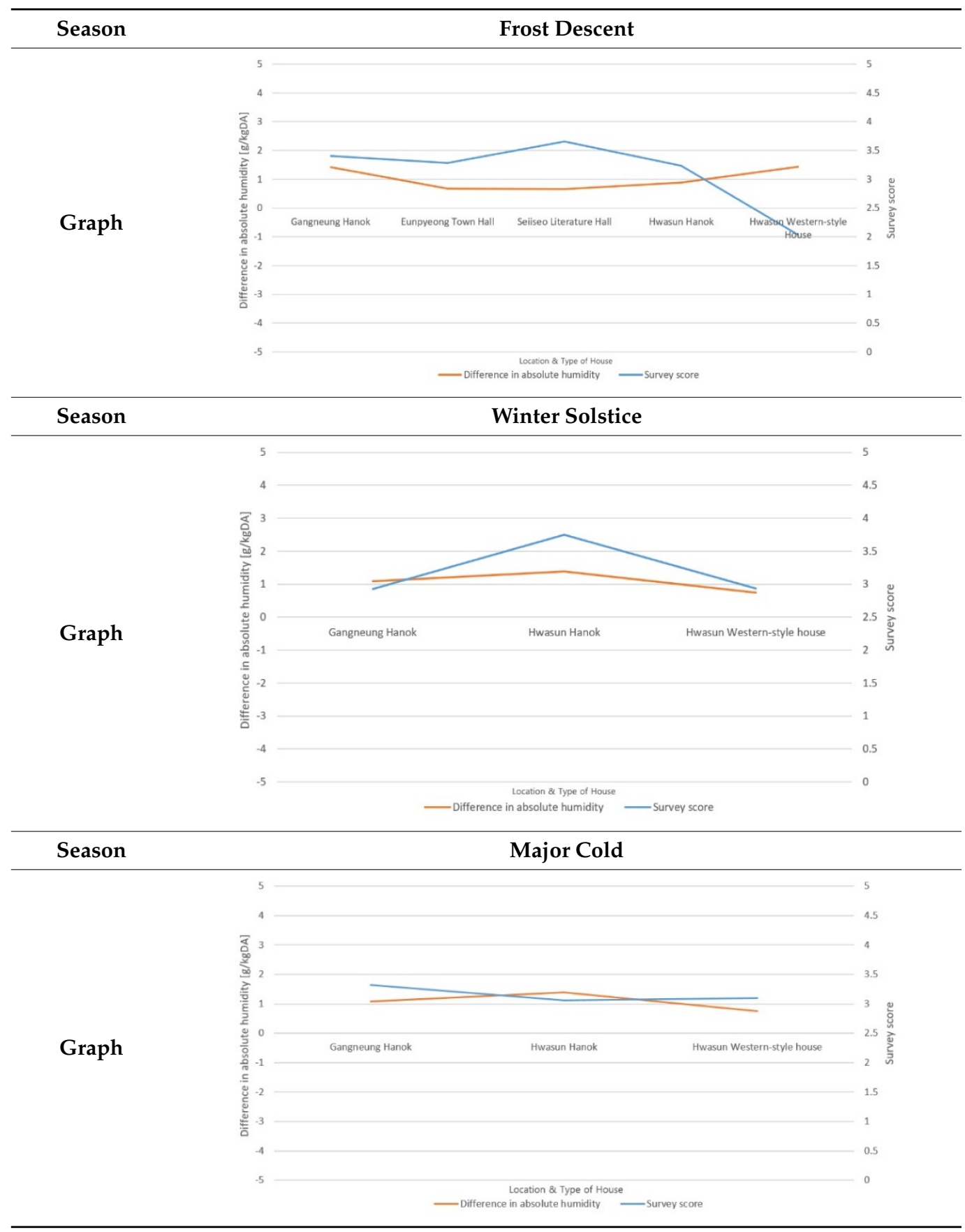

Through comparison of the graphs, it was possible to examine the scores of changes in satisfaction according to the decrease and increase in the difference in absolute humidity by season. In summer solstice or major heat, it is apparent that as the absolute humidity difference decreases, the user survey satisfaction increases. In the case of winter solstice and major cold, the difference of measured absolute humidity was all around $1 \mathrm{~g} / \mathrm{kgDA}$, but the survey scores were recorded differently depending on the region and the housing type. In the case of frost descent, the relationship was unclear.

\subsubsection{Analysis and Results (Humidity)}

To statistically analyze the correlation between the physical indicator and the survey, the Pearson correlation coefficient was calculated. For statistical analysis, IBM SPSS Statistics program was used. Table 6 shows the derived values. 
Table 6. Pearson correlation coefficient and significance probability.

\begin{tabular}{|c|c|c|c|c|c|}
\hline Division & $\begin{array}{l}\text { Summer } \\
\text { Solstice }\end{array}$ & $\begin{array}{c}\text { Major } \\
\text { Heat }\end{array}$ & $\begin{array}{c}\text { Frost } \\
\text { Descent }\end{array}$ & $\begin{array}{l}\text { Winter } \\
\text { Solstice }\end{array}$ & $\begin{array}{c}\text { Major } \\
\text { Cold }\end{array}$ \\
\hline Pearson Correlation Coefficient & $-0.332 * *$ & $-0.549 * *$ & -0.147 & -0.059 & -0.018 \\
\hline Significance Probability & $<0.001^{* *}$ & $<0.001^{* *}$ & 0.107 & 0.580 & 0.865 \\
\hline
\end{tabular}

The Pearson correlation coefficient was calculated through 524 surveys collected during the five seasons (one-hundred thirty-one parts for summer solstice, eighty-five parts for major heat, one-hundred thirty-two parts for frost descent, ninety-two parts for winter solstice, ninety-four parts for major cold period). The Pearson correlation becomes meaningful when the significance probability is less than 0.05 . Therefore, the analysis was conducted of the summer solstice and major heat whose significance probability was less than 0.001 as marked with asterisks in the table. The summer solstice and major heat period were analyzed to have a negative correlation. The degree was more pronounced as the major heat was 0.549 . For summer solstice, it was derived as 0.332 . When analyzing the variance, the degree of freedom (F) was measured to be 15.991, and the significance probability was measured to be less than 0.001 . Also, the unnormalized coefficient of the constant was measured to be 0.33 . The unnormalized coefficient for the survey mean score was measured as -0.239 . The significance probability was 0.001 or less. Based on this, the regression equation of Equation (2) was derived:

Absolute humidity difference $=0.33-0.239 \times$ Survey average score (Summer Solstice)

In the case of major heat, when analyzing the variance, the degree of freedom (F) was measured to be 35.750 , and the significance probability was measured to be less than 0.001 . The unnormalized coefficient for the constant was 1.128, while the unnormalized coefficient for the average score of the questionnaire was 1.215. The significance probability was 0.001 or less. Based on this, the regression equation of Equation (3) was derived:

Absolute humidity difference $=1.128-1.215 \times$ Survey average score $($ Major Heat $)$

Based on this, the following sintering can be made. First, the difference in absolute humidity of summer solstice or major heat has a significant correlation with the average of the survey. This was confirmed through the derivation of the Pearson correlation. Second, based on this, regression equations, such as Equations (2) and (3), were derived. Using these regression equations, it is possible to infer the difference between the absolute humidity of the summer solstice and the major heat corresponding to the score above the satisfaction score. In addition, through surveys on summer solstice and major heat, it is expected that a reverse inference on the humidity control performance of the living hanok will be possible. However, in this study, there are limitations in applying Equations (2) and (3) to the field, because physical measurements were not made for the various hanok, but measurements were made for representative hanok. Therefore, the analysis needs to be based on more samples.

\subsection{Insulation Analysis}

\subsubsection{Measurement of Physical Indicators (Insulation)}

The physical index of insulation is calculated by the heat transmission rate. The heat transmission rate is calculated as the reciprocal of the total heat resistance of the structure. In KS A 6300, comfort is evaluated by measuring the heat permeation of the outer wall, the top floor, and the bottom floor. Total heat resistance can be calculated through the heat resistance coefficient and the thickness of each material used in the building. Table 7 shows the heat resistance values of hanoks to be analyzed with Gangneung Hanok, Eunpyeong Village Hall, Literature Hall at Eunpyeong Village, and Hwasun Hanok and those were calculated through the heat resistance coefficient and thickness of each material used in them. 
Table 7. Heat resistance of each part.

\begin{tabular}{ccccc}
\hline Division & $\begin{array}{c}\text { Gangneung } \\
\text { Hanok }\end{array}$ & $\begin{array}{c}\text { Eunpyeong } \\
\text { Village Hall }\end{array}$ & $\begin{array}{c}\text { Literature Hall at } \\
\text { Eunpyeong Village } \\
\text { Literature Hall }\end{array}$ & $\begin{array}{c}\text { Hwasun } \\
\text { Hanok }\end{array}$ \\
\hline Exterior Wall & $2.931 \mathrm{~m}^{2} \mathrm{k} / \mathrm{W}$ & $5.561 \mathrm{~m}^{2} \mathrm{k} / \mathrm{W}$ & $3.824 \mathrm{~m}^{2} \mathrm{k} / \mathrm{W}$ & $2.255 \mathrm{~m}^{2} \mathrm{k} / \mathrm{W}$ \\
Top Floor Roof & $5.325 \mathrm{~m}^{2} \mathrm{k} / \mathrm{W}$ & $7.011 \mathrm{~m}^{2} \mathrm{k} / \mathrm{W}$ & $2.742 \mathrm{~m}^{2} \mathrm{k} / \mathrm{W}$ & $1.51 \mathrm{~m}^{2} \mathrm{k} / \mathrm{W}$ \\
Bottom Floor & $6.105 \mathrm{~m}^{2} \mathrm{k} / \mathrm{W}$ & $3.166 \mathrm{~m}^{2} \mathrm{k} / \mathrm{W}$ & $3.490 \mathrm{~m}^{2} \mathrm{k} / \mathrm{W}$ & $2.153 \mathrm{~m}^{2} \mathrm{k} / \mathrm{W}$ \\
\hline
\end{tabular}

Table 8 shows that the energy-saving design standards for apartment houses presented in Korea are based on different heat resistance for each region. Compared to this value, it was confirmed that the Gangneung Hanok satisfies $70.34 \%, 79.87 \%$ and $100 \%$ for the exterior wall, roof and floor, respectively. Eunpyeong Village Hall meets 100\%,100\% and $75.98 \%$, Literature Hall at Eunpyeong Village meets $91.77 \%, 41.13 \%$ and $83.75 \%$, and in the case of Hwasun Hanok, 72.16\%, 27.18\% and 66.74\% are satisfied respectively. Most hanok did not meet this criterion. In the poor part, it meets the standard of less than $30 \%$.

Table 8. Heat resistance standard of each region.

\begin{tabular}{ccccc}
\hline Division & Central Region 1 & Central Region 2 & Southern Region & Jeju Island \\
\hline Exterior Wall & $5.882 \mathrm{~m}^{2} \mathrm{k} / \mathrm{W}$ & $4.167 \mathrm{~m}^{2} \mathrm{k} / \mathrm{W}$ & $3.125 \mathrm{~m}^{2} \mathrm{k} / \mathrm{W}$ & $2.439 \mathrm{~m}^{2} \mathrm{k} / \mathrm{W}$ \\
Top Floor Roof & $6.667 \mathrm{~m}^{2} \mathrm{k} / \mathrm{W}$ & $6.667 \mathrm{~m}^{2} \mathrm{k} / \mathrm{W}$ & $5.556 \mathrm{~m}^{2} \mathrm{k} / \mathrm{W}$ & $4 \mathrm{~m}^{2} \mathrm{k} / \mathrm{W}$ \\
Bottom Floor & $4.762 \mathrm{~m}^{2} \mathrm{k} / \mathrm{W}$ & $4.167 \mathrm{~m}^{2} \mathrm{k} / \mathrm{W}$ & $3.226 \mathrm{~m}^{2} \mathrm{k} / \mathrm{W}$ & $2.439 \mathrm{~m}^{2} \mathrm{k} / \mathrm{W}$ \\
\hline
\end{tabular}

\subsubsection{Survey Score (Insulation)}

The degree of insulation that a person experiences tends to fluctuate with the maintenance of room temperature on a cold day. However, in the case of winter solstice and major cold, only Gangneung Hanok and Hwasun Hanok were comparable. Therefore, the scope of the analysis was limited to frost descent. In addition, since the climate is different for each region, the energy conservation design standard, which can be the standard for each region, was used. A comparison was conducted between the satisfaction rate of energy-saving design insulation standards, and the survey on the sense of insulation that users feel on cold days, and through this, the comfort insulation standards of hanok could be inferred. Therefore, the actual satisfaction ratio was calculated compared to the heat resistance standards of each region.

In the case of frost descent, Gangneung Hanok recorded the highest insulation satisfaction survey score with 3.65 points. On the other hand, Hwasun Hanok recorded the lowest score with 1.98 points. When comparing the degree of insulation of the exterior walls of Gangneung Hanok and Hwasun Hanok, the satisfaction rate of Hwasun Hanok's heat resistance standard by region was $72.16 \%$, which is higher than that of Gangneung of $70.34 \%$. Looking at such a phenomenon, it can be inferred that the degree of insulation of the outer wall does not have a significant effect on the insulation that a person feels. Eunpyeong Village Hall recorded the second lowest score, despite having a 100\% satisfaction rate on the heat resistance criteria for each region in the wall and roof. Literature Hall at Eunpyeong Village had a better floor heat resistance value than the Eunpyeong Village Hall, and the questionnaire evaluation also recorded a higher score. Looking at this from a primary perspective, it shows a direction similar to the heat resistance of the floor and the score of the user survey, which is judged to reflect the peculiarity of hanok for a sedentary lifestyle. Figure 3 shows the relationship between heat resistance and survey score. 


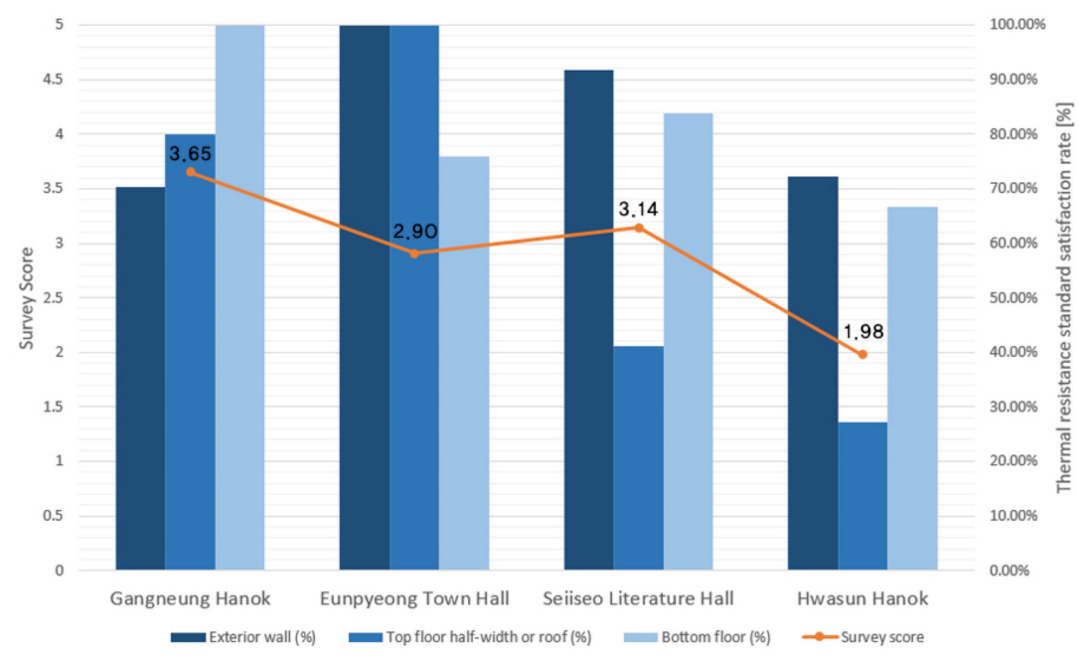

Figure 3. Comparison of heat resistance and survey scores (Frost Descent).

\subsubsection{Analysis and Results (Insulation)}

Table 9 shows the Pearson correlation coefficient for each site and user satisfaction score that were derived. In the case of the outer wall, the significance probability was 0.127 , which did not show much significance in the correlation. For roofs and floors, the probability of significance was measured to be less than 0.001 , which was significant. The roof had a positive correlation of 0.425 , and the floor had a positive correlation of 0.539 . The floor was found to have a higher relationship than the roof.

Table 9. Pearson correlation between heat resistance and survey score.

\begin{tabular}{cccc}
\hline Division & Exterior Wall & Top Floor Roof & Bottom Floor \\
\hline Pearson Correlation Coefficient & -0.148 & $0.425^{* *}$ & $0.539^{* *}$ \\
Significance Probability & 0.127 & $<0.001^{* *}$ & $<0.00^{* *}$ \\
\hline
\end{tabular}

Based on these results, multiple regression analysis was conducted on the heat resistance of the roof and floor. In the case of the roof, when the linear regression model was applied, the significance probability was 0.596 , which was not significant. When the analysis was conducted based only on the bottom floor, $\mathrm{R}$ was derived as 0.539 , and $\mathrm{R}$ squared was 0.291 , representing $29.1 \%$ of explanatory map. When analyzing the variance, the degree of freedom (F) was measured to be 43.01 , and the probability of significance was measured to be less than 0.001 as marked with asterisks in the table. In addition, the unnormalized coefficient of the constant was measured at 69.70 , and the non-normalized coefficient of the survey average score was measured at 2.154. The significance probability was 0.001 or less. Based on this, the regression equation of Equation (4) was derived:

Heat resistance satisfaction rate by region $(\%)=69.7+2.154 \times$ Survey average score (Frost Descent)

Sintering is as follows. First, when comparing the heat resistance of the exterior wall, roof, and floor with the user survey score, the most significant indicator was the heat resistance of the floor. This is expected to be highly related to the sedentary lifestyle characteristics of the hanok. Second, based on the heat resistance of the floor, a regression equation such as Equation (4) was derived. This has limitations, because it is a simple linear regression equation for frost descent. Therefore, it needs to be re-analyzed with more samples, and the range must also be established. 


\subsection{Condensation Analysis}

\subsubsection{Measurement of Physical Indicators (Condensation)}

Condensation can be evaluated through TDR, and design standards are currently being provided to prevent condensation in apartment houses [30]. Condensation is determined by calculating the TDR based on the entrance door, the wall joint, and the window in contact with the outside air. The modern hanok uses modern technology in the case of doors and windows to improve performance. Therefore, hanok and western-style houses have TDR differences at the junction of the walls.

Therm 7.6 software from the Windows \& Daylighting group was used for TDR analysis of the wall joints. Therm 7.6 is a condensation evaluation simulation program that infers the surface minimum temperature (SMT) considering the indoor temperature (IT), outdoor temperature $(\mathrm{OT})$, underground temperature, and heat resistance of the wall. TDR simulation was conducted based on the actual temperature data for each season, and the wall composition in the detailed drawings. TDR calculations were carried out twice. The first was calculated based on the daily average indoor temperature, outdoor temperature, and underground temperature. Second, TDR was calculated for the early morning hours (0:00-6:00), where the difference between indoor and outdoor temperatures is large. For Gangneung Hanok, Eunpyeong Village Hall, and Literature Hall at Eunpyeong Village, the maximum TDR was measured at 0.18, and for Hwasun Hanok, it was measured at 0.29. Table 10 shows the calculated TDR.

Table 10. Temperature difference ratio (TDR) simulation of wall joint.

Target


Table 10. Cont.

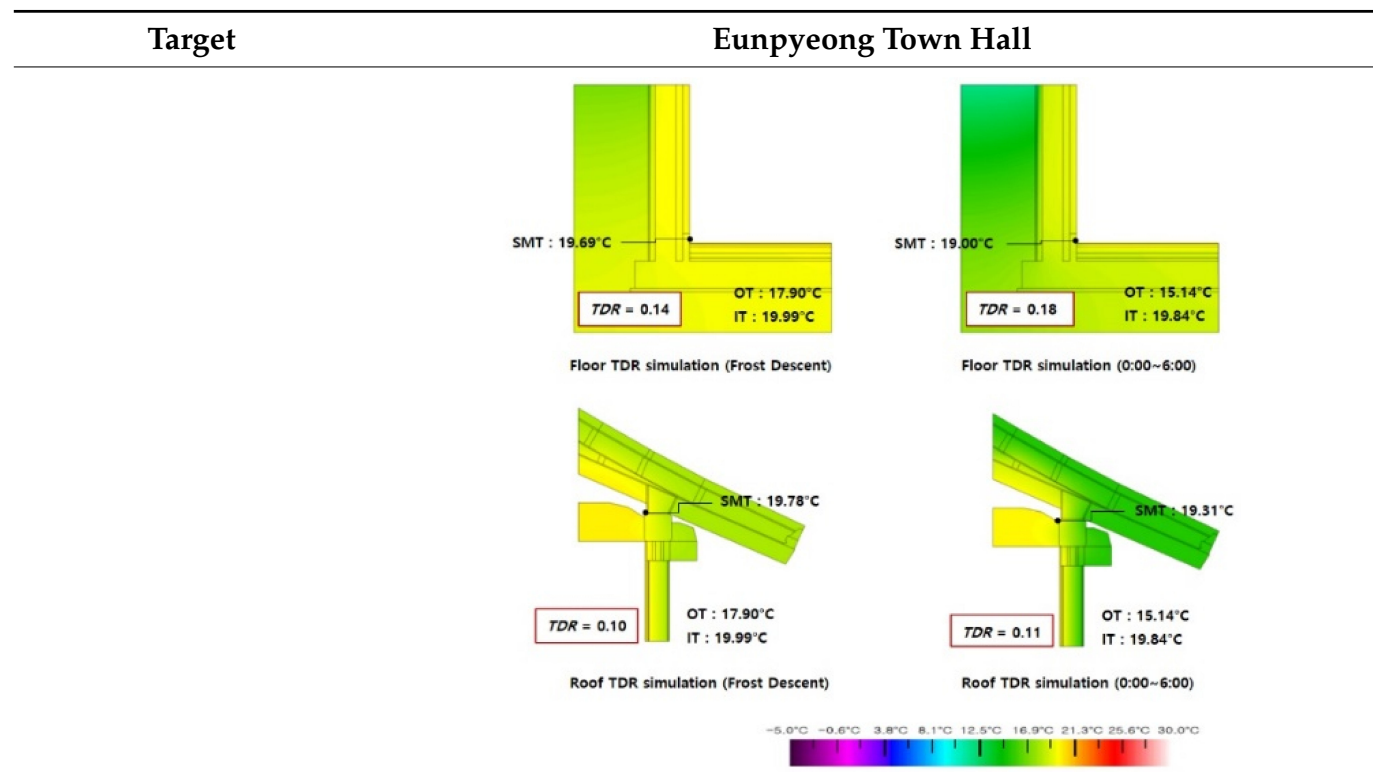

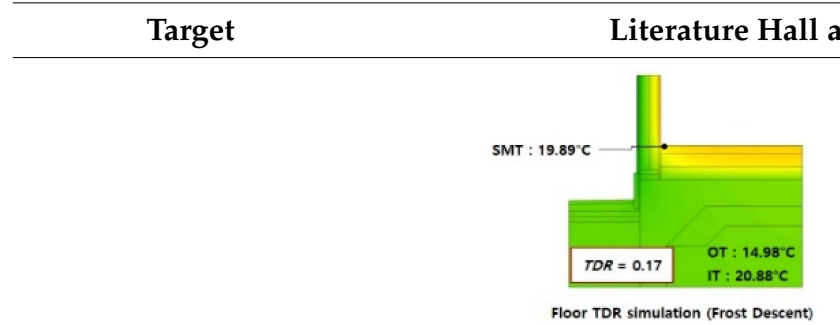

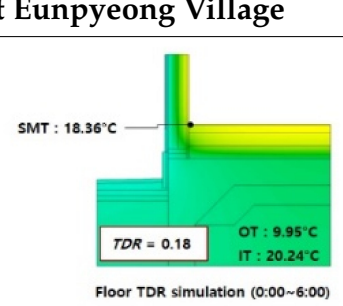

TDR Simulation

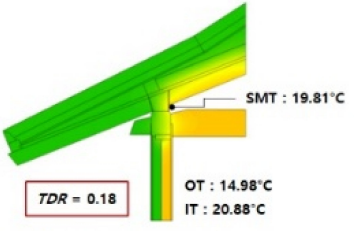

Roof TDR simulation (Frost Descent)

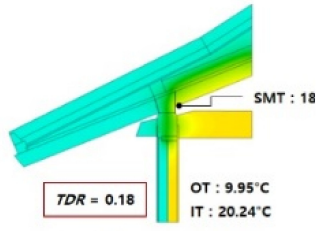

Roof TDR simulation (0:00 6:00)

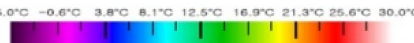

Target




\subsubsection{Survey Score (Condensation)}

A survey was conducted on frost descent, winter solstice, and major cold, which may cause condensation, and overall high scores were recorded. In the case of frost descent, Gangneung recorded the highest score with 4.12 points, while Literature Hall at Eunpyeong Village recorded the lowest score with 3.57 points. During the same period, Eunpyeong Town Hall scored 3.67 and Hwasun Hanok scored 3.84. In particular, Gangneung Hanok scored 4.05 survey points for the winter solstice, and 4.01 points for the major cold. Hwasun Hanok with the highest TDR score was 4.00 points during the winter solstice period, and 4.19 points during the major cold period. The Eunpyeong Town Hall and Literature Hall at Eunpyeong Village were not surveyed for those periods, and Table 11 shows the measured scores.

Table 11. Condensation survey score.

\begin{tabular}{cccc}
\hline Division & Frost Descent & Winter Solstice & Major Cold \\
\hline Gangneung Hanok & 4.12 & 4.05 & 4.01 \\
Eunpyeong Town Hall & 3.67 & - & - \\
Literature Hall at Eunpyeong Village & 3.57 & - & - \\
Hwasun Hanok & 3.84 & 4.00 & 4.19 \\
\hline
\end{tabular}

\subsubsection{Analysis and Result (Condensation)}

According to the design standards for preventing condensation in apartment houses, Gangneung Hanok, Eunpyeong Village Hall, and Literature Hall at Eunpyeong Village require a performance of TDR 0.26 at the wall joint. Hwasun Hanok requires TDR 0.28 performance. Gangneung Hanok, Eunpyeong Village Hall, and Literature Hall at Eunpyeong Village meet this requirement. In the case of Hwasun Hanok, this performance is not exhibited due to slight differences, but the TDR 0.29 shows performance that is close to the requirements. Based on this, it is considered that hanok can sufficiently meet the design standards for condensation prevention of apartment houses proposed in the existing laws and regulations, and it is judged to have a high degree of satisfaction with condensation.

\section{Conclusions}

In this study, an analysis of spatial comfort (humidity, insulation, condensation) among the physical comfort performances of hanok was conducted. The physical indicator complied with KS A 6300, which was suggested as a method of measuring the comfort performance of hanok, but it was partially modified and used to suit the actual situation of the hanok. KS A 6300 does not provide an evaluation standard, only a method to measure the comfort of a hanok. Research is needed to establish a standard of comfort performance compared to user satisfaction. This study was conducted as a review to establish standards. Therefore, a study on the correlation between satisfaction and physical indicators was conducted through user surveys to suggest preliminary standards for the hanok comfort evaluation based on spatial indices.

The significance of the study is as follows. First, a methodological review of the establishment of evaluation criteria was conducted by comparing the physical indicators and satisfaction scores through user surveys. Second, a modified measurement method was proposed for the humidity measurement method, which is difficult to measure in the field, and the effectiveness of the method was proven through statistical analysis. In KS A 6300, a part of the wall must be removed or manufactured, and tested for moisture absorption and moisture resistance. However, it is difficult to apply the evaluation to a hanok that is actually in use. Therefore, a measurement method based on the difference in absolute humidity was devised, and it was confirmed that it is valid through comparison with the user satisfaction score. Third, an equation was derived to establish physical performance targets for some items. Regression equations for the seasons were derived for humidity control and insulation properties. Through this, it became possible to establish a goal of physical indicators to approach the satisfaction score required by users in the design stage. 
However, this study also has the following limitations. First, the sample for evaluation targets must be expanded. In this study, only Gangneung Hanok, Eunpyeong Village Hall, Literature Hall at Eunpyeong Village, and Hwasun Hanok were analyzed. Physical indicators and surveys should be conducted for a number of hanok, but only analysis of samples limited by temporal and spatial limitations was conducted. Second, long-term observation need to be performed. In this study, only representative seasons and hanok were analyzed. Therefore, observations and surveys over a long period of time are necessary for accurate analysis, and it is necessary to accumulate them.

To overcome these limitations, a method for analyzing surveys through smart devices may be suggested. If surveys are collected from people living in hanok from time to time, and the physical indicators at that time are converted into a database through measurement sensors, statistical data will be accumulated, and will be more accurate. In addition, it is expected that it will be possible to infer the physical performance of the hanok in residence through the questionnaire response that considers the characteristics of the surveyor. To do this, it is also necessary to consider the operation of big data.

If a regression equation with high precision is derived through this method, it could be meaningful as a standard for evaluating comfort performance while the only method is presented in KS A 6300 currently. In addition, the capability of designers themselves are more critical to build a hanok in Korea but their decisions tend to be too subjective, since those are excluded from the contemporary legal system for managing the insulation of properties etc. Therefore, it is expected that burdens from hanok designers who should consider and/or prove their performances quantitatively will be reduced if the evaluation criteria are institutionalized with official clues such as advanced standards proposed by the following research. Furthermore, the specificity of vernacular housing could be reflected in certification systems such as LEED and BREEAM, if the proposed methods are not just applied to Korea and other regions worldwide as well.

Author Contributions: J.-H.K. and S.-H.H. designed the research settings; J.-H.K. performed the evaluations; J.-H.K. and S.-H.H. analyzed the data; S.-H.H. verified the analysis results; J.-H.K. and S.-H.H. wrote the paper. All authors have read and agreed to the published version of the manuscript.

Funding: This research was funded by Ministry of Land and Transport Affairs of the Korean Government (Project No: 21AUDP-B128638-05).

Institutional Review Board Statement: Not applicable.

Informed Consent Statement: Not applicable.

Acknowledgments: This research was supported by a grant from the Urban Architecture Research Program (Technology Development of Design and Construction for Large-Space Hanok over 10 Meters, Development of Hanok Technology, Phase III).

Conflicts of Interest: The authors declare no conflict of interest.

\section{References}

1. Zarghami, E.; Fatourehchi, D.; Karamloo, M. Impact of daylighting design strategies on social sustainability through the built environment. Sustain. Dev. 2017, 25, 504-527. [CrossRef]

2. Moore, T.; Doyon, A. The uncommon nightingale: Sustainable housing innovation in Australia. Sustainability 2018, 10, 3469. [CrossRef]

3. Abel, C. Eco-culture, development and architecture. Knowl. Policy 1993, 6, 10-28. [CrossRef]

4. Yahya, Q.; Kemi, A.; Stephen, E. Eco-cultural design assessment framework and tool for sustainable housing schemes. Urban Sci. 2020, 4,65 .

5. Leadership in Energy and Environmental Design. LEED v4 for Building Design and Construction. 2019. Available online: https:/ / www.usgbc.org/resources/leed-v4-building-design-and-construction-current-version (accessed on 24 June 2021).

6. Building Research Establishment Environmental Assessment Method. BREEAM International New Construction Technical Manual. 2016. Available online: https://www.breeam.com/discover/technical-standards/newconstruction (accessed on 24 June 2021).

7. Burcu, S.; Ömer, F.B.; Atacan, A.; Kofi, A. Sustainable features of vernacular architecture: Housing of eastern Black Sea region as a case study. Arts 2017, 6, 11. 
8. Jang, I. A Study on Natural Friendly Elements of the Traditional Design Symbolizing Hanok: Focuses on Materials and Structures. Master's Thesis, University of Dongguk, Seoul, Korea, 2011.

9. Choi, H.; Ahn, K. Assessing the sustenance and evolution of social and cultural contexts within sustainable urban development, using as a case the MAC in South Korea. Sustain. Cities Soc. 2013, 6, 51-56. [CrossRef]

10. Green Standard for Energy and Environmental Design. G-SEED Green Building Certification Standards. 2016. Available online: http:/ / www.gseed.or.kr/boardOpenDetailPage.do?rnum=5\&bbsCnt=1370\&bbsId=12 (accessed on 24 June 2021).

11. Kwon, Y.; Kim, S.; Jeon, B. Unraveling the factors determining the redevelopment of Seoul's historic hanoks. Habitat Int. 2014, 41, 280-289. [CrossRef]

12. Yang, K.; Hwang, H.; Kim, S.; Song, J. Development of a cementless mortar using Hwangtoh binder. Build. Environ. 2007, 42, 3717-3725. [CrossRef]

13. Sim, J.; Sim, J. The atmospheric environmental impact of a Korean traditional building's life cycle, along with carbon footprint analysis. Sustain. Cities Soc. 2017, 28, 172-186. [CrossRef]

14. Lee, J.; Park, J. Phase Change Material (PCM) application in a modernized Korean traditional house (hanok). Sustainability 2018, 10, 948. [CrossRef]

15. Lee, M.; Cheon, D.; Han, S. An AHP analysis on the habitability performance toward the modernized hanok in Korea. Buildings 2019, 9, 177. [CrossRef]

16. Lee, M.; Cheon, D.; Han, S. A technical assessment of comfort performance of hanok using comparative field surveys between experts and users. Sustainability 2020, 12, 10315. [CrossRef]

17. Christos, E.; Stefan, T. The valuation of aesthetic preferences and consequences for urban transport infrastructures. Sustainability 2021, 13, 4977.

18. Kim, J.; Han, S. Analysis of standardized factor coefficient for building aesthetics by types of colored BIPV-Focused on the color factor. KIEAE J. 2020, 20, 135-141. [CrossRef]

19. Kim, T.; Han, S. Development of real-time comfort monitoring system and indoor environment control system for hanok village. J. Korea Inf. Commun. Soc. 2015, 2015, 1574-1575.

20. Ministry of Trade, Industry and Energy. Report on Standardization Development of Comfort and Environmental Characteristics of Traditional Hanok. 2017. Available online: https:/ / scienceon.kisti.re.kr/srch/selectPORSrchReport.do?cn=TRKO201800040273 (accessed on 24 June 2021).

21. Korean Agency for Technology and Standards. KS A 6300 Examination Method for Hanok. Available online: https: / / standard.go.kr/KSCI/standardIntro/getStandardSearchView.do? menuId=919\&topMenuId=502\&upperMenuId=503\& $\mathrm{ksNo}=\mathrm{KSA}$ 6300-1\&tmprKsNo=KS_A_NEW_2016_4005\&reformNo=00 (accessed on 24 June 2021).

22. Korean Agency for Technology and Standards. KS F 2611 Hygrothermal Performance of Building Materials and ProductsDetermination of Moisture Adsorption/Desorption Properties in Response to Humidity Variation. Available online: https: / / standard.go.kr/KSCI/standardIntro/getStandardSearchView.do? $m e n u I d=919 \&$ topMenuId=502\&upperMenuId=50 $3 \& \mathrm{ksNo}=\mathrm{KSF} 2611 \& \mathrm{tmprKsNo}=\mathrm{KSF} 2611 \&$ reformNo=02 (accessed on 24 June 2021).

23. International Organization for Standardization. ISI 24353:2008 Hygrothermal Performance of Building Materials and ProductsDetermination of Moisture Adsorption/Desorption Properties in Response to Humidity Variation. Available online: https: / / www.iso.org/standard/42167.html (accessed on 24 June 2021).

24. Park, J. Study on Humidity Control Performance of the Interior Finishing Materials of Museum Collection Storage: Focused on Comparisons between Natural Timber and Artificial Humidity Control Materials. Master's Thesis, University of Yonsei, Seoul, Korea, 2005.

25. Ministry of Land, Infrastructure, and Transport. Notification No. 2017-881. Available online: http://www.molit.go.kr/USR/I020 4/m_45/dtl.jsp?idx=15270 (accessed on 24 June 2021).

26. Ministry of Land, Infrastructure, and Transport. Notification No. 17344. Available online: https:/ /www.law.go.kr/LSW/lsInfoP. do? efYd=20201210\&lsiSeq=218777\#0000 (accessed on 24 June 2021).

27. Lee, J. Study on the Evaluation of Thermal Insulation Performance of Hanok Walls through the Model Experiment. Master's Thesis, Chonbuk National University, Jeollabukdo, Korea, 2020.

28. Korean Agency for Technology and Standards. KS F 2295 Test Method of Dew Condensation for Windows and Doors. Available online: https: / / standard.go.kr/KSCI/standardIntro/getStandardSearchView.do?menuId=919\&topMenuId=502\&upperMenuId= $503 \& \mathrm{ksNo}=\mathrm{KSF} 2295 \& \mathrm{tmprKsNo}=\mathrm{KSF} 2295 \&$ reformNo=09 (accessed on 24 June 2021).

29. Han, B.; Kim, G. Expectation on occurrence probability of condensation in apartment buildings. Korean Soc. Sci. Art 2015, 19, 725-733. [CrossRef]

30. Ministry of Land, Infrastructure, and Transport. Notification No. 2016-835. Available online: https://www.law.go.kr/\%ED $\% 96 \% 8$

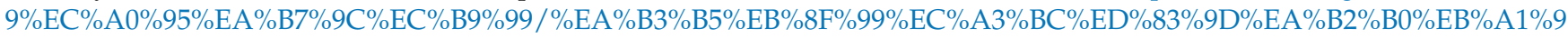

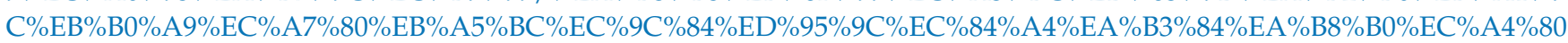
(accessed on 24 June 2021).

31. Meteorological Agency of Korea. Weather Data Open Portal. Available online: https://data.kma.go.kr/cmmn/main.do (accessed on 13 October 2021). 